\title{
Experimental Validation of Numerical Structural Dynamic Models for Metal Plate Joining Techniques
}

Journal Title

$\mathrm{XX}(\mathrm{X}): 1-18$

(C) The Author(s) 2017

Reprints and permission:

sagepub.co.uk/journalsPermissions.nav

DOI: 10.1177/ToBeAssigned

www.sagepub.com/

@SAGE

\section{Van Belle ${ }^{1,2}$, D. Brandolisio ${ }^{1,2}$, E. Deckers ${ }^{1,2}$, S. Jonckheere ${ }^{1,2}$, C. Claeys ${ }^{1,2}$, B. Pluymers ${ }^{1,2}$, W. Desmet ${ }^{1,2}$}

\begin{abstract}
Joined structures are of high industrial relevance. The dynamic effects of joints are however often practically difficult to accurately account for in numerical models, as they often lead to local changes in stiffness and damping. This paper discusses the comparison between measurements and simulations of joined panels considering four different joining techniques: adhesive bonding, metal inert gas welding, resistance spot welding and flow drill screwing. An experimental modal analysis is performed on the different systems and the Power Injection Method is applied to determine the loss factors of single plate systems and their joined counterparts. The joined panels are modeled in a holistic simulation environment with particular focus on the joining region, by application of predefined and generic joint models. A very good agreement is obtained between the simulated dynamic behavior and the experimental results, showing that an accurate representation of the joints has been obtained.
\end{abstract}

\section{Keywords}

Modal Analysis, Joint Modeling, Finite Element Analysis, Lightweight, Power Injection Method

\section{Introduction}

With the ever increasing computational power and need for Computer Aided Engineering tools to judge the effects of design choices on virtual prototypes rather than time- and cost-expensive physical prototypes, a modeling environment that can accurately represent the influence of design choices on the dynamic system behavior is indispensable. In the EU FP7 collaborative research project ALIVE (ALIVE (2012)), aiming for a multi-material, lightweight body-inwhite vehicle development, this need is underlined in the context of investigating the field of joining technologies in order to allow various materials to be fastened securely and lastingly. A modeling environment is required that allows an accurate representation of the joints and their effect on the dynamic system behavior. To this end, the holistic modeling environment LMS Virtual.Lab (Siemens PLM Software (2015b)) is used to model different predefined joint types, based on simplified and mesh independent connection models using the Finite Element Method (FEM) (Zienkiewicz et al. (2005)), in contrast to the often considered very detailed and complex models in literature.

Different punctual and continuous joining technologies are considered by the ALIVE consortium to join aluminum parts, but also high performance steel. The consortium has been looking at mechanical technologies, welding technologies, one side access technologies and adhesives. Therefore, the joining techniques studied in this paper are adhesive bonding, metal inert gas (MIG) welding, resistance spot welding (RSW) and flow drill screwing (FDS).

Adhesive bonding In adhesive bonding (Kinloch (1987)), two materials are joined by applying an intermediate glue layer (Fig. 1). During an annealing phase, a polymerization reaction of the organic molecules in the glue forms strongly interconnected long polymer chains. Depending on the adhesive, this reaction can be initiated by UV light, pressure, heat. .

Glued connections can be typically applied to any material, making this technique very versatile. Moreover, the

\footnotetext{
${ }^{1} \mathrm{KU}$ Leuven, Department of Mechanical Engineering Celestijnenlaan 300 - box 2420

3001 Heverlee, Belgium

${ }^{2}$ Member of Flanders Make
}

Corresponding author:

L. Van Belle, KU Leuven, Department of Mechanical Engineering, Celestijnenlaan 300 - box 2420, 3001 Heverlee, Belgium

Email: lucas.vanbelle@kuleuven.be 


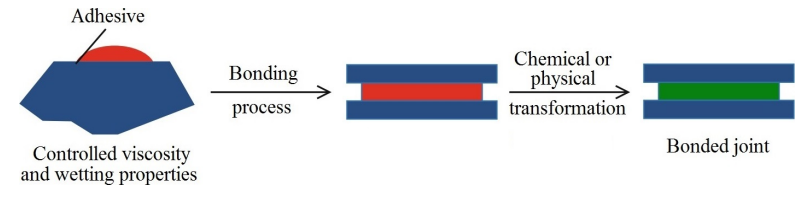

Figure 1. Adhesive bonding process (da Silva et al. (2011))

temperatures involved are typically lower than in the case of friction drilling or welding. However, long curing times may be necessary and care must be taken in extreme environments to avoid degradation of the glue.

The simulation of glued parts is often done in an explicit way (Sauer (2016)) using flexible solid elements with (visco)elastic material properties for the glue (Anderson et al. (1973); Wu and Crocombe (1996)). The models of parts and glue can either be joined by direct elimination, or through rigid body elements (RBE).

The structural dynamic behavior of adhesive bonding has been subject of extensive research (He (2011)). The effect of various adhesive parameters, such as material and geometric properties, on the structural dynamic behavior has been analyzed using analytic models (Vaziri et al. (2004)) as well as very detailed FE models (He (2012a, 2014); He and Oyadiji (2001); Kaya et al. (2004); Gunes et al. (2007)) including validations with experimental measurements of natural frequencies and frequency response functions (Vaziri et al. (2004); He (2012b); Aruleswaran et al. (2001)), mainly for simple beam or plate lap-joint configurations. The FE models used in these studies rely on very refined solid element meshes of the adhesive layer, implying meshdependent modeling and computationally expensive models.

In this work, the use of a simplified FE model for adhesive bonding as automated in the holistic Virtual.Lab environment, relying on a combination of solid elements connected to the adherents through multi point constraints (MPC), is validated experimentally on a simple lap-joint configuration.

Metal inert gas welding Metal inert gas welding (Minnick (2007)) uses a filler metal as electrode (Fig. 2). An electric arc forms between a consumable wire electrode and the metal parts. The melting of metals is obtained by the heat generated by the electric arc that explodes inside a protective inert gas atmosphere (argon or argon + helium) continuously injected on the arc. It is a very versatile welding technique, capable of joining most metals in most positions and geometries.

MIG welded parts can be considered similar to spot welded connections, for which the modeling is discussed below, with the difference that there are no weld nuggets

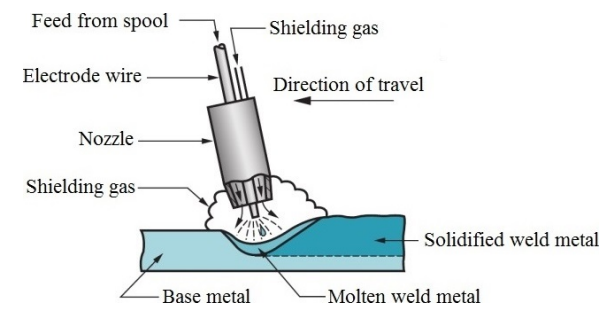

Figure 2. Metal inert gas welding process (Groover (2007))

where the material is locally joined, but there is a continuous seam of joined material. For the modeling of MIG welded parts, detailed FE models can be used, connecting the joined structure meshes through solids or shells, meshing the weld bead geometry in detail, or by rigid connections (Chee and Bakar (2007)). Some simplified FE models for seam weld connections are discussed by Aygül in (Aygül (2012)), albeit in a fatigue analysis context. The joined structures can be connected using oblique shell elements or shell elements of increased thickness vicinity (Niemi (1995); Niemi and Marquis (2003); Eriksson et al. (2003)), rigid links (Fayard et al. (1997)) or using solid elements.

Despite being a well-established joining technology, especially for single material connections, no extensive experimental validation of structural dynamic FE modeling for seam welded structures, MIG welded structures in particular, is currently reported in literature. Horton et al. validate a simplified 2D FE model for an $\mathrm{H}$-frame structure comprising fillet and butt bevel welds, by comparison with experimentally obtained modes and natural frequencies in (Horton et al. (1999)). The structural dynamic behavior of MIG welded dissimilar metal plates is analyzed using solid FE modeling and verified experimentally by Hatifi et al. in (Hatifi et al. (2014)), while various FE models for seam welded T-joined plates are compared with measurements by Chee and Bakar in (Chee and Bakar (2007)).

In this paper, a simplified structural dynamic FE model for seam welds, relying on a nearest node RBE2 modeling between the joined faces, is applied to a simple lap-joint configuration and verified experimentally.

Resistance spot welding Resistance spot welding (RSW) (Zhang and Senkara (2005)) is a quick and economic process without filler metal which uses the combined effects of a mechanical pressure and an electric current (Fig. 3). Parts to be welded are superimposed and locally fixed between two copper alloy electrodes. Parts and electrodes are crossed by a welding current which causes an important increase of temperature by Joule's effect; this creates a node of fused material. 


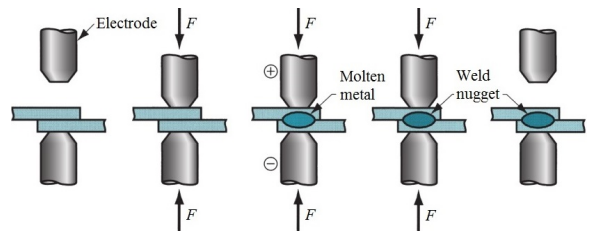

Figure 3. Resistance spot welding process (Groover (2007))

RSW has the major advantage that it is both quick and economic. However, for some materials, such as some aluminum alloys, the higher thermal and electrical conductivity require high welding currents. Moreover, it can only produce localized joints, and it is not very suitable for joining parts with complicated geometries.

Several approaches to model spot welds in an FE scheme are available (Palmonella et al. (2005); Xu and Deng (2004)), using a spider web of RBEs, rigid or flexible solid elements or a combination of both.

Of the four joining technologies considered in this work, resistance spot welding has received the most attention in literature, while the use of spot weld FE models in industry is widespread. A distinction is made between models that require the stress within the spot welds to be calculate and models that do not (Palmonella et al. (2005)). The first type requires very detailed models, which leads to computationally intensive models, especially when large amounts of spot weld are present in e.g. a full vehicle model (Ouisse and Cogan (2010)), that not necessarily accurately predict the stiffness of the spot welds. Simplified FE spot weld models are investigated by $\mathrm{Xu}$ and Deng in $\mathrm{Xu}$ and Deng (2004)), with a focus on static problems. For structural dynamic analysis, the Nastran CWELD and ACM2 (CHEXA+RBE3) models are well established in automotive industry (Palmonella et al. (2004, 2005); Ouisse and Cogan (2010)) and included in automatic spot weld modeling procedures. These models have been widely investigated, from parameter and mesh sensitivities, validation and model updating with experiments on simple plate assemblies to increase accuracy (Lardeur et al. (2012); Palmonella et al. (2004, 2005); Kuratani et al. (2011)), to application to joined vehicle components (Lardeur et al. (2012); Krank et al. (2012)) and full vehicle models (Ouisse and Cogan (2010)). Good agreement is obtained, with the ACM2 model generally found to result in the most accurate representation. In some recent works, other simplified FE models for spot welds are suggested (Alvarez et al. (2014)), which can further increase the robustness and mesh-independent RSW FE modeling.

Adding to the experimental validations in literature, in this work, the state of the art Nastran CHEXA-RBE3 (ACM2)

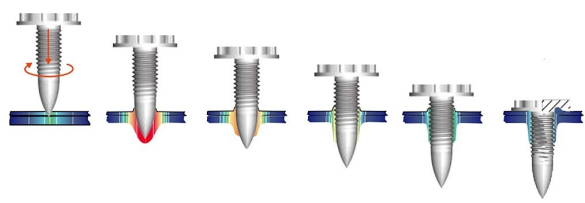

Figure 4. Flow drill screwing process (Skovron et al. (2015))

model and its implementation in the Virtual.Lab holistic environment is applied and validated experimentally.

Flow drill screwing In flow drill screwing (FDS) (Miller et al. (2006)), a high pressure and a high rotational speed (up to $8000 \mathrm{rpm}$ ) are applied to the fastener (Fig. 4). Consequently, the sheet part is heated by the friction between the fastener and the part. A notch is initiated and the conical tip of the fastener penetrates into the material. In the lightly molten material pool, the thread forms and the fastener is screwed in.

This procedure allows screwing without any (undesired) metal chipping. Moreover it is a very quick process and it works with almost any kind of metal. This type of connection is able to transfer high pull-out as well as shearing forces. Nevertheless, the method is limited to relatively thin parts and materials with a good thermal stability.

For the FDS joining technology, although a common technique for joining dissimilar materials used in vehicle assemblies, no dedicated FE models for structural dynamic analysis are readily available. In the work of Sønstabø et al. (Sønstabø et al. (2016)), the macroscopic modeling of flow drill screw connections for static problems is addressed by assessing the ability to capture the behavior of the FDS connections of five state-of-the-art existing FE models for adhesive bonding, spot welding and self-pierce riveting. Together with their previous work (Sønstabø et al. (2015)), these analyses are limited to static problems and the current lack of experimental dynamic testing data for FDS connections in literature is underlined.

To analyze the structural dynamic behavior of FDS connections using FE modeling, similar to Sønstabø et al. (Sønstabø et al. (2016)), inspiration can be sought in stateof-the-art structural dynamic FE models for bolted joints (Kwon et al. (2006); Kim et al. (2007); He and Zhu (2011); Shokrollahi and Adel (2016)) or rivet connections (Dourado and de Meireles (2014); He et al. (2007b,a)), for which the Virtual.Lab environment contains simplified FE models.

In this work, experimental structural dynamic measurements on FDS joined plates are presented, and a comparison is made with a bolted joint FE model. As Kim et al. (Kim et al. (2007)) show, three different approaches can be followed: (i) an explicit bolt model using solid 
elements, (ii) a spider web of RBE's, (iii) no explicit bolt model where the preload of the bolt is directly applied to the joined parts. Here, a spider based simplified bolted joint FE model is applied, to assess its representativeness. Contrary to Sønstabø et al. (Sønstabø et al. (2016)), no further updating and tuning of the connection model parameters is aimed for, as this requires a more detailed in-depth study.

As discussed above, the use of commercial FE packages and automated connection generation is well established, in for example automotive industry. However, of the four considered joining techniques, only simplified FE models for structural dynamic analysis for RSW modeling have currently undergone extensive validation and tuning in literature. The objective of this paper is to broaden the analysis of the structural dynamic behavior of the four joining techniques and to provide experimental validations of simplified, mesh-independent FE connection models for structural dynamic analysis of joined systems, from the well-established and validated RSW models to the less or not experimentally validated models for adhesive bonding, MIG welding and flow drill screwing. The FE modeling is performed in the holistic LMS Virtual.Lab environment, allowing the implemented automated connection modeling procedures to be validated, which consequently offer a great advantage in modeling effort. While the majority of the experimental validations in literature focus on the correlation of natural frequencies and mode shapes, in this work, experimentally obtained damping values are taken into account in the FE models and the experimental validation is extended with the assessment of the frequency response function magnitudes.

Single, as well as joined plate configurations are modeled in the holistic simulation environment and an experimental modal analysis is performed for the experimental validation. The Power Injection Method (PIM) (Carfagni and Pierini $(1999 a, b))$ is used to determine the loss factors of the different plates and the joined systems. By comparing the numerical simulations and the experimental results, the holistic environment is shown to be a promising tool for the structural dynamic modeling of joined systems considering the four mentioned joining techniques. This paper is organized as follows. After introducing the joined plate geometries and material properties in Section 2, the PIM is explained in Section 3, followed by the measurements for single plates in Section 4 and joined plates in Section 5. In Section 6 the numerical models and comparison between measurements and simulations are presented. The main conclusions are summarized in Section 7.

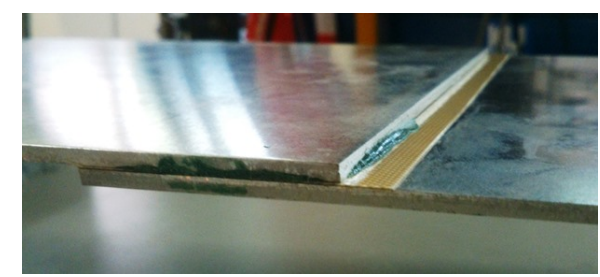

Figure 5. Adhesive bonding, with Teflon tape residue

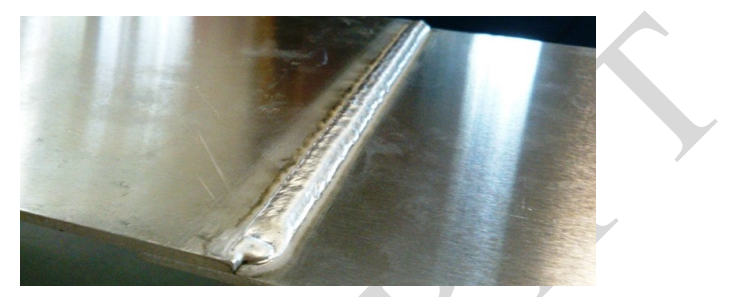

Figure 6. MIG weld connection

\section{Materials and configurations}

In this paper, both punctual and continuous joining technologies are considered to join aluminum and also high performance steel. The materials considered are Al 6082-T6, Al 6016-T4 and phs-ultraform 1500 press-hardened steel, with material properties as shown in Table 1 . These values are used to calculate damping values, as described in Section 3 , and for the material definitions in the numerical models.

As there are still a lot of unknowns concerning the simulation of joints and their influence on the area directly around them, an assembly of two A4 metal plates with a controlled geometry and joining configuration is considered. Table 2 summarizes the different assemblies, where the overlap is made along the short edge of the plates. Both single A4 plates of every material as well as joined A4 panels are tested, as discussed in Sections 4 and 5.

For the adhesive bonding (Fig. 5) a green Sika adhesive is used with properties detailed in Table 1 . A $0.3 \mathrm{~mm}$ thick glue layer is applied in the middle of the overlap along the entire width of the plates by the use of $0.3 \mathrm{~mm}$ diameter microbeads. The width of the glue layer is controlled to be $12.5 \mathrm{~mm}$ using Teflon tape, to which the glue does not adhere. The curing is done at the same time for the considered joined plates. All these factors should lead to good repeatability for this connection.

For the MIG weld connection (Fig. 6) the seam comprises the entire plate width. As MIG welding is typically a onesided access joining technique, the weld is made only at one edge of the joined plates. Unlike the adhesive bonding, the controllability of the start and end position of the weld bead is lower which leads to a slightly lower repeatability.

For the resistance spot welding (Fig. 7) the parts are welded together using welds of $5 \mathrm{~mm}$ diameter nominally, 
Table 1. Materials and properties considered: Young's modulus $E$, Poisson's ratio $\nu$ and density $\rho$

\begin{tabular}{ccccc}
\hline & Al 6082-T6 & Al 6016-T4 & phs-ultraform 1500 & Sika glue \\
\hline$E$ & $69.5 \mathrm{GPa}$ & $69 \mathrm{GPa}$ & $210 \mathrm{GPa}$ & $2 \mathrm{GPa}$ \\
$\nu$ & 0.346 & 0.3 & 0.3 & 0.36 \\
$\rho$ & $2700 \mathrm{~kg} / \mathrm{m}^{3}$ & $2700 \mathrm{~kg} / \mathrm{m}^{3}$ & $7850 \mathrm{~kg} / \mathrm{m}^{3}$ & $1250 \mathrm{~kg} / \mathrm{m}^{3}$ \\
\hline
\end{tabular}

Table 2. Overview of material combinations and joining geometries for each joining technique

\begin{tabular}{ccccc}
\hline & Adhesive bonding & MIG & RSW & FDS \\
\hline Plate 1 & $\mathrm{Al} 6082-\mathrm{T} 6$ & $\mathrm{Al} 6082-\mathrm{T} 6$ & $\mathrm{Al} 6016-\mathrm{T} 4$ & phs-ultraform 1500 \\
& $296 \times 210 \times 2.5 \mathrm{~mm}$ & $296 \times 210 \times 2.5 \mathrm{~mm}$ & $296 \times 210 \times 1 \mathrm{~mm}$ & $296 \times 210 \times 1.5 \mathrm{~mm}$ \\
Plate 2 & $\mathrm{Al} 6082-\mathrm{T} 6$ & $\mathrm{Al} 6082-\mathrm{T} 6$ & $\mathrm{Al} 6016-\mathrm{T} 4$ & $\mathrm{Al} 6082-\mathrm{T} 6$ \\
& $296 \times 210 \times 2.5 \mathrm{~mm}$ & $296 \times 210 \times 2.5 \mathrm{~mm}$ & $296 \times 210 \times 1 \mathrm{~mm}$ & $296 \times 210 \times 2.5 \mathrm{~mm}$ \\
Overlap & $38 \mathrm{~mm}$ & $19 \mathrm{~mm}$ & $19 \mathrm{~mm}$ & $17 \mathrm{~mm}$ \\
\hline
\end{tabular}

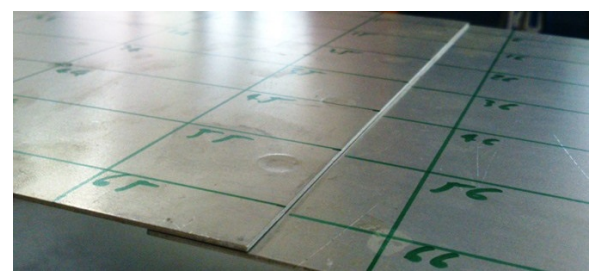

Figure 7. Spot weld connection

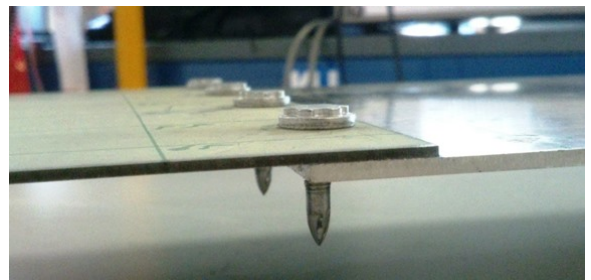

Figure 8. FDS connection

ensuring a sufficiently strong joint. The spot welds are located at the middle of the overlap, with a mutual separation of $50 \mathrm{~mm}$ and a distance of $30 \mathrm{~mm}$ from the edge.

For the FDS connection (Fig. 8) screws of diameter $5 \mathrm{~mm}$ and screw head diameter $13 \mathrm{~mm}$ are drilled in the middle of the overlap, at the same locations as the spot welds. For this connection, a $1.5 \mathrm{~mm}$ press hardened steel ultraform 1500 sheet is combined with a $2.5 \mathrm{~mm} \mathrm{Al} \mathrm{6082-T6} \mathrm{sheet.} \mathrm{The}$ steel sheet was too hard for the screws to penetrate, which has caused the need for pre-punched pilot holes of $7.8 \mathrm{~mm}$. Possible misalignment of screws and pre-holes can cause lower repeatability for this connection type.

\section{Power Injection Method}

Through experimental analysis, the variability between samples of different materials and joining techniques is evaluated and structural damping coefficients are estimated for later use in the numerical simulations. There are three methods commonly used for the determination of the structural damping loss factor $\eta$ in dynamic systems (Cremer et al. (2005); Heylen et al. (2014)). The first method, called the Impulse Response Decay Method, is based on the rate of decay of the system response at resonance frequency. The analysis is carried out in the time domain and can only be performed for one frequency at a time. The second method, called the Half Power Bandwidth Method, is based on the calculation of the frequency response decay in the neighborhood of a resonance frequency. Also this method allows the evaluation of the damping at the resonance frequencies. Both methods, however involve several difficulties, especially when the frequency range of interest is modally dense, and modes are closely spaced. Alternatively, the Power Injection Method (PIM) (Carfagni and Pierini (1999a,b)) can be used. The PIM is used to obtain an estimate of the damping coefficient based on the comparison of the stored and dissipated by the system (Martinez et al. (2009)). Frequency-averaged loss factors can be obtained from experiments of structures under steady-state vibration. These loss factors are widely used in numerical vehicle modeling using FEM and Statistical Energy Analysis (De Langhe and Sas (1996); Bloss and Rao (2002)).

As no acoustic measurements are performed, acoustic radiation damping is not separately accounted for, but inherently included in the structural damping loss factor, considered to be the only dissipation mechanism present. Under this assumption, the power $P_{i n}$ injected into the system, in this case a single plate, equals the dissipated power $P_{\text {diss }}$ :

$$
P_{i n}=P_{d i s s}=\omega \eta E_{t o t},
$$

where $E_{t o t}$ is the total energy of the system, averaged over a cycle of vibration, $\omega$ is the angular frequency and $\eta$ the damping loss factor. The input power is proportional to the velocity $v_{i}=\mathrm{j} \omega u_{i}$ of the system at the excitation point

$$
P_{i n}(\omega)=\frac{1}{2} R e\left[j \omega u_{i}(\omega) F^{*}\right],
$$


with $\mathrm{j}^{2}=-1$ and $F^{*}$ the complex conjugate of the input force. This can be rewritten using the input point mobility transfer function $H_{i i}$

$$
P_{i n}(\omega)=\frac{1}{2} R e\left[H_{i i}(\omega)\right]\left|F_{i}\right|^{2} .
$$

In terms of transfer mobility functions, the total energy is given by

$$
E_{t o t}=\frac{1}{2}\left|F_{i}\right|^{2} \sum_{j=1}^{N} m_{j}\left|H_{i j}(\omega)\right|^{2},
$$

where $H_{i j}$ is the cross-mobility transfer function between point $i$ and $j$ and $N$ is the total amount of response points. According to the measurement grid, a portion of the total mass is associated with the $j$-th point, indicated by $m_{j}$. Consequently, the damping loss factor can be evaluated as

$$
\eta(\omega)=\frac{R e\left[H_{i i}(\omega)\right]}{\omega \sum_{j=1}^{N} m_{j}\left|H_{i j}(\omega)\right|^{2}}
$$

In this study, $H_{i i}$ and $H_{i j}$ are evaluated through measurements in the software LMS Test.Lab (Siemens PLM Software (2015a)) and $\eta$ is computed in Matlab. Some experimental errors may be introduced, especially when evaluating $H_{i i}$ (Bies and Hamid (1980); Libardi and Vartoto (2004)). For example, $P_{i n}$ may be negative at some frequencies. Additionally, since a matrix inversion is needed to obtain $\eta$, small experimental errors will be enlarged, However, the damping prediction is generally unbiased in correspondence of the resonance frequencies of the system, which are the most important to estimate the damping coefficient. To reduce even more such an error, the response is averaged over $200 \mathrm{~Hz}$ frequency bands and three excitation locations. Mean values for $\eta$ over the entire frequency range up to $1000 \mathrm{~Hz}$ are calculated for use in the numerical FE models. The FE equations of motion are:

$$
\mathbf{M} \ddot{\mathbf{u}}(t)+\mathbf{K}_{\mathbf{T}} \mathbf{u}(t)=\mathbf{F}(t),
$$

with mass matrix $\mathbf{M}$, complex stiffness matrix $\mathbf{K}_{\mathbf{T}}$ and excitation force F. Structural damping is introduced by introducing $\eta$ in $\mathbf{K}_{\mathbf{T}}$ as follows, using a Nastran solver (Rose (2002); Radoičić and Jovanović (2013)):

$$
\mathbf{K}_{\mathbf{T}}=\mathbf{K}+\mathrm{j} \sum \mathbf{K}_{\mathbf{E}} \eta_{E}
$$

with $\mathbf{K}$ and $\mathbf{K}_{\mathbf{E}}$ the global stiffness matrix and element stiffness matrix respectively. Applying these constant values for $\eta$ in the numerical models over the whole frequency range of interest is expected to result in a reasonable approximation of the experimental results.

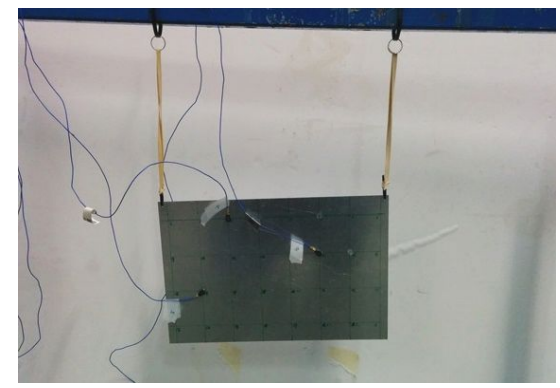

Figure 9. Experimental test set-up for single plate system

\section{Single plate systems}

\subsection{Measurement setup}

An experimental modal analysis is performed on single plates of each material in Table 1 to obtain the dynamic properties. For each material, measurements are performed on three different samples under free-free boundary conditions obtained by suspending the samples from two bungees, which have very low stiffness in the out-ofplane direction and consequently do not influence the bending deformation (Fig. 9). The test grid consists of 32 regularly spaced points such that all modes can be observed up to $1000 \mathrm{~Hz}$, chosen to represent the low- to mid-frequency region for vehicle NVH (Gagliardini et al. (2005)). The reciprocity principle is applied by using a roving hammer (PCB piezotronics, model 086C03) approach and measuring the responses with fixed accelerometers (PCB piezotronics, model 352A24) in three positions: $(0.09,0.18) \mathrm{m},(0.21,0.13) \mathrm{m}$ and $(0.05,0.08) \mathrm{m}$ with $(0,0) \mathrm{m}$ located in the bottom left corner of the plates. The software LMS Test.Lab is used to process the experimental data obtained with an LMS Scadas III data acquisition system. The variability in the samples of the different materials is studied and structural damping coefficients are estimated with the PIM to use in the numerical simulations.

\subsection{Measurement results}

The variability between the samples is studied by both the Modal Assurance Criterion (MAC) as well as the relative standard deviation (RSD) of the resonance frequencies $f_{\text {res }}$ :

$$
\operatorname{RSD}\left(f_{\text {res }}\right)=\frac{\sigma\left(f_{\text {res }}\right)}{\mu\left(f_{\text {res }}\right)},
$$

with $\sigma(\cdot)$ the standard deviation and $\mu(\cdot)$ the mean. For each material the MAC matrices for the modes up to 1000 $\mathrm{Hz}$ between two tested samples are reported in Fig. 10 to indicate the degree of agreement between their mode shapes. The RSD of the resonance frequencies in Fig. 11 is plotted 
as function of the average resonance frequency to show the spread amongst the tested samples.

The MAC matrices show an excellent agreement between the mode shapes for the Al 6082-T6 plates, with a near unity diagonal. For the Al 6016-T4 plates, also a very good agreement is obtained, with values of 0.95 and higher. For the phs-ultraform 1500 plates, the MAC matrix, compared to the aluminum panels, shows slightly lower, yet still good correspondence. All the samples are cut from a larger plate, introducing a small permanent bending, as shown in Fig. 12. Such a bending leads to stiffening effects, for which some modes show higher resonance frequencies and variability over the samples. The steel plates show higher bending than aluminum, leading to a larger variability of the resonance frequencies. For Al 6082-T6 hardly any bending is present, corresponding to the excellent agreement found. Over the analyzed frequency range, comparing different samples leads to good MAC values, meaning that the mode shapes are not much influenced by the bending of the plate. In general, a good to excellent repeatability is obtained.

The structural damping loss factor $\eta$ is calculated for each sample using the PIM, and is plotted as function of frequency in Fig. 13. The values are averaged over $200 \mathrm{~Hz}$ bands. Larger damping loss factors are found at low frequencies. This might be caused by the suspension used for the free-free boundary condition and by the fact that the first modes can be affected by the permanent bending. The thinnest Al 6016-T4 plate shows the highest damping value, while the thicker Al 6082-T6 and phs-ultraform 1500 panels show similar, lower damping values. A mean value is calculated over the entire frequency range apart from the first band, for later use in the numerical simulations for the joined assemblies. These values, together with the maxima and minima, are shown in Table 3.

\section{Joined plate systems}

For the joined plates, a modal analysis is performed on three samples for each joining technique. The variability between the different samples is assessed and the damping loss factors are calculated using the PIM.

\subsection{Measurement results}

As for the single plates, free-free boundary conditions obtained by suspending the samples from two bungees (see Fig. 14). For the experimental modal analysis, a grid of 70 points is used and a roving hammer approach is adopted with accelerometers in five fixed positions (Table 4).
The MAC matrices between two tested samples up to $1000 \mathrm{~Hz}$ are presented in Fig. 15 for all joining techniques. The RSD of the resonance frequencies is given in Fig. 16. Over the considered frequency range, comparing different samples for each of the joining technologies indicates good repeatability and low variability as for the single plates.

The MAC matrices for adhesive bonding (Fig. 15a) and MIG welding (Fig. 15b) show very good agreement, as was also found for the single Al 6082-T6 plates. The high degree of similarity can also be found in the continuous joining technique, as opposed to the pointwise connections for RSW and FDS. The adhesive bonded samples are continuously joined, with a reproducible thickness and width, and the different samples are cured at the same time. However, thickness variations can occur when an excess of glue is present between the adherents and the Teflon tape used for aligning the glue strip (Fig. 17). The very good agreement in the MAC matrix together with the lowest deviation of the resonance frequencies show that for the adhesive bonding the most repeatable results are obtained. For MIG welding, some eigenfrequencies show higher deviations than for the adhesive bonded samples. For some of the samples, on the one hand the welding line is passed to the other face of the joined region (Fig. 18a), meaning a complete merging of the two plates, while on the other hand the quality of beginning and end of the weld bead is not easily repeated (Fig. 18b).

For RSW, the MAC matrix in Fig. 15c shows good correspondence between eigenmodes, but some differences appear at higher frequencies. The RSD of the resonance frequencies indicates that mainly below $500 \mathrm{~Hz}$ a higher variability is present. The spacing of $50 \mathrm{~mm}$ between the spot welds can also have an influence. When half the bending wavelength in the Al 6016 T4 panel equals the distance between two spot welds, both plates can detach between adjacent welds and nonlinear effects can be introduced. The half wavelength frequency is calculated as $961 \mathrm{~Hz}$ (Fahy and Kalnins (1987)). This is near the end of the frequency range considered, involving only the last two modes, and consequently not of importance here. Comparing these results to the MAC matrices and RSDs for the single Al 6016-T4 plates, the slight increase in variability can mainly be attributed to the connection, which can contain variations in alignment, effective weld diameter and material parameters in the weld zone.

The MAC matrix for the FDS connection (Fig. 15d) also shows very good agreement of the modeshapes. Some slightly lower MAC values are found as compared to those for the adhesive bonding and MIG welding. Looking at the variability on the resonance frequencies, the FDS samples 


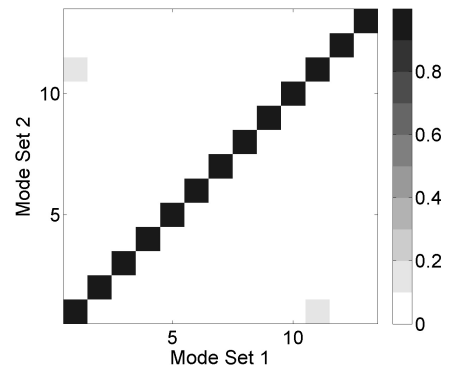

(a) Al 6082-T6

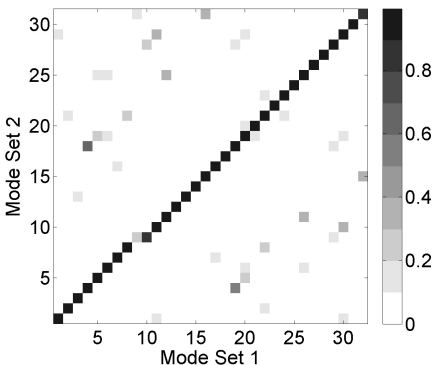

(b) Al 6016-T4

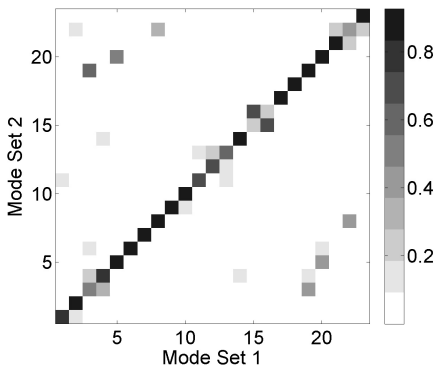

(c) phs-ultraform 1500

Figure 10. MAC for two of the tested single plates per material

Table 3. Average values of the damping loss factors calculated with the PIM for the single plates for the three materials considered

\begin{tabular}{cccc}
\hline Center frequency [Hz] & Al 6082-T6 & Al 6016-T4 & phs-ultraform 1500 \\
\hline $\mathbf{1 0 0}$ & 0.0077 & 0.0146 & 0.0050 \\
$\mathbf{3 0 0}$ & 0.0025 & 0.0064 & 0.0023 \\
$\mathbf{5 0 0}$ & 0.0013 & 0.0052 & 0.0018 \\
$\mathbf{7 0 0}$ & 0.0012 & 0.0033 & 0.0014 \\
$\mathbf{9 0 0}$ & 0.0015 & 0.0021 & 0.0024 \\
\hline Mean & 0.0016 & 0.0043 & 0.0020 \\
\hline Mean min & 0.0011 & 0.0033 & 0.0016 \\
Mean max & 0.002 & 0.0053 & 0.0022 \\
\hline
\end{tabular}

Table 4. Accelerometer positions used in the measurements of the joined plates, with origin $(0,0) \mathrm{m}$ at the center of the overlap

\begin{tabular}{ccccc}
\hline Point & Adhesive bonding & MIG & RSW & FDS \\
\hline $\mathbf{2 8}$ & $(0.1465,0.03) \mathrm{m}$ & $(0.1475,0.03) \mathrm{m}$ & $(0.1475,0.03) \mathrm{m}$ & $(0.148,0.03) \mathrm{m}$ \\
$\mathbf{4 4}$ & $(-0.0915,-0.03) \mathrm{m}$ & $(-0.0875,-0.03) \mathrm{m}$ & $(-0.0875,-0.03) \mathrm{m}$ & $(-0.088,-0.03) \mathrm{m}$ \\
$\mathbf{5 2}$ & $(-0.2015,-0.06) \mathrm{m}$ & $(-0.2075,-0.06) \mathrm{m}$ & $(-0.2075,-0.06) \mathrm{m}$ & $(-0.208,-0.06) \mathrm{m}$ \\
$\mathbf{6 6}$ & $(0.0365,-0.09) \mathrm{m}$ & $(0.0275,-0.09) \mathrm{m}$ & $(0.0275,-0.09) \mathrm{m}$ & $(0.028,-0.09) \mathrm{m}$ \\
$\mathbf{7 0}$ & $(0.2565,-0.09) \mathrm{m}$ & $(0.2675,-0.09) \mathrm{m}$ & $(0.2675,-0.09) \mathrm{m}$ & $(0.268,-0.09) \mathrm{m}$ \\
\hline
\end{tabular}

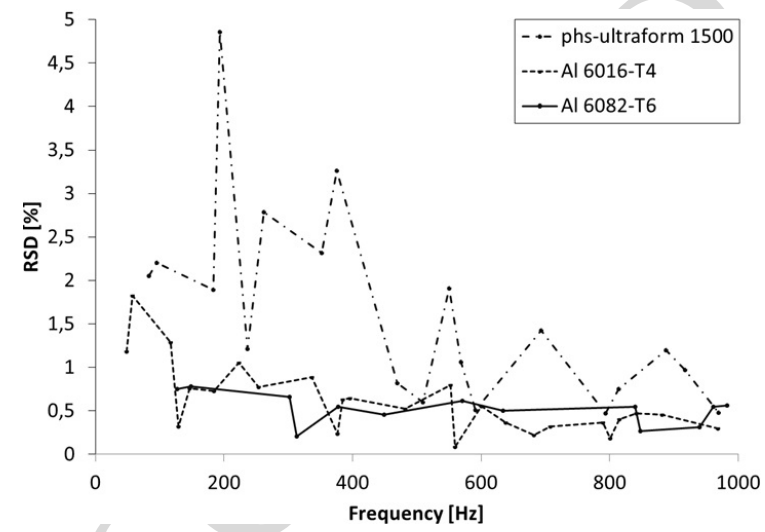

Figure 11. RSD of the resonance frequencies for the tested single plates

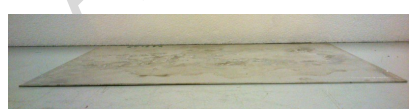

(a) Al 6016-T4

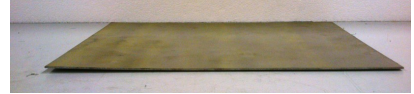

(b) phs-ultraform 1500
Figure 12. Permanent cutting-induced bending in the single plates

show overall higher deviation than the other connection types. As for the single plates, the cutting process introduces

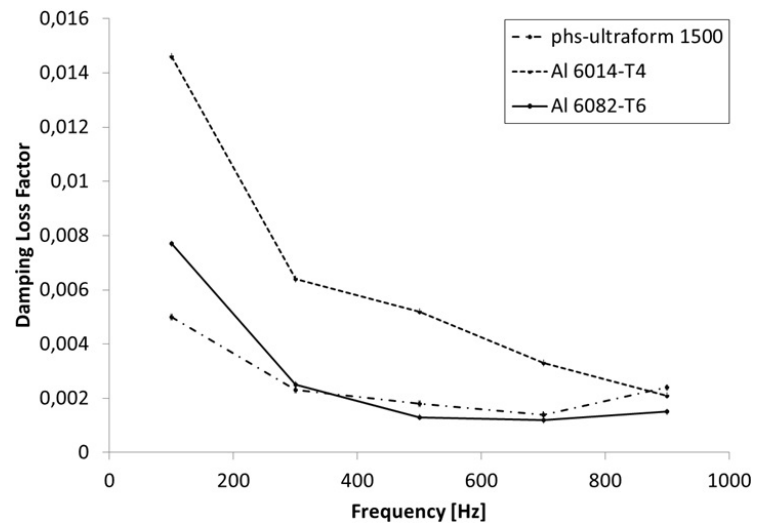

Figure 13. Damping loss factors for the tested single plates

a permanent bending, especially for the phs-ultraform 1500 steel plate of the FDS samples (Fig. 19). As for single plates, the highest degree of variability can thus be found for the FDS samples. Another influence might be found in misalignment of the FDS screws with the pilot holes made in the steel plates, leading to difference in geometry between the samples. Similar to the spot welded plates, local detachment could occur between adjacent screws. However, for the thicker panels involved, the frequency from which on 


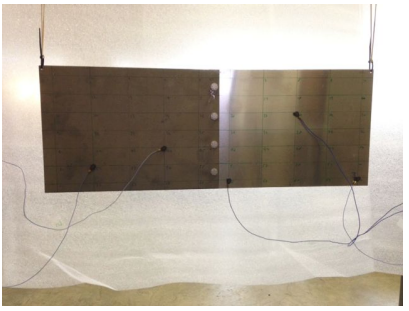

(a) Free boundary conditions

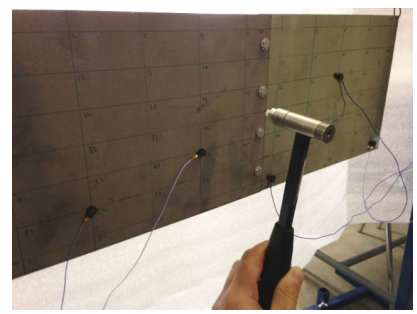

(b) Roving hammer approach
Figure 14. Experimental test set-up for the joined plate system

this behavior is expected is beyond the frequency range of interest.

\subsection{Damping loss factors}

In applying the PIM for assemblies, the idea was to retrieve the coupling loss factor (CLF) related to the different joining techniques, using the same principle as for single plates, with a modified formulation (Clarkson and Ranky (1984)). As in the joined systems the plates are dynamically strongly coupled, identifying the CLF using the multi-system approach did not yield accurate results (Bies and Hamid (1980); Libardi and Vartoto (2004)). Therefore the single system approach is adopted. The joined plates are evaluated as a single plate/system, thus calculating a loss factor value for the entire system to be able to compare with the loss factors of the involved single plates and extract information on the joint.

In Fig. 20, the damping loss factors are shown. Contrary to the results for the single plates, the damping loss factors for the first frequency band are very similar to those of the other bands. Therefore, in the calculation of the mean damping loss factor, the results for the first frequency band are taken into account. These values are listed in Table 5. From Fig. 20, the MIG welded and adhesive bonded samples are seen to behave very similar. This can be explained by the fact that both are line connections and are applied to the same $\mathrm{Al}$ 6082-T6 plates. The bonded sample shows a slightly higher damping value, which might be caused by the use of glue as opposed to aluminum of the host structures for joining (see Fig. 17). The bonded samples also show Teflon tape residue which can, together with excess glue remains, induce higher damping. For the spot welded plates, the highest damping is found, as the thinnest $\mathrm{Al}$ 6016-T4 plates are used.

The loss factors of the joined samples listed in Table 5 and those of the individual plates in Table 3 can be compared. A slight increase of loss factor is found for bonding and to very minor extent also for MIG welding. For FDS and RSW, values seem to reduce, most likely due to the very low inherent damping in the material, the non-linear effects introduced with a non-continuous joining and residual effects from the free-free boundary condition. Since the loss factors of the joined plates are close to those of the constituting bare plates, the coupling does not seem to be very influent in the total loss evaluation. The comparison reveals that in the considered frequency range the different joining techniques do not substantially influence the damping values. Consequently, using the mean damping values obtained for the single plates over the frequency range of interest in the numerical models described in the following section is expected to lead to a reasonable approximation.

\section{Comparison numerical models and measurements}

A holistic simulation environment LMS Virtual.Lab is used which allows efficient FE modeling and analysis of connections for NVH. For the joined samples, the socalled Generic Connections are used; the Generic Glue, Seam Weld, Spot Weld and Screw Connection are used to model the adhesive bonding, MIG welding, RSW and FDS respectively. These Generic Connections allow for mesh-independent modeling, in which connections are added between subsystems without modifying their meshes, which is one of the requirements of the ALIVE project.

The FE meshes for each of the separate plates consist of 2D quadrilateral shell elements (CQUAD4) with a maximum element size of $5 \mathrm{~mm}$, based on the geometries given in Table 2. This element size complies with the simulation requirements of the ALIVE project and satisfies the criterion of 6 elements per wavelength for bending waves up to at least $1000 \mathrm{~Hz}$. The material parameters from Table 1 are used in the isotropic material definitions for the plates. For the structural damping, the mean damping values from Table 3 obtained using the PIM are applied: 0.0016 for $\mathrm{Al} 6082$ T6, 0.0043 for Al 6016-T4 and 0.0020 for phs-ultraform 1500. For each connection, as shell elements in mid-surface representation are used, the distance between the plates is the mean of the two plate thicknesses, except for the adhesive bonded case where the thickness of the glue layer is taken into account. To allow a proper comparison, the meshes are based on the measurement grid with response locations (points 28, 44, 52, 66 and 70) and excitation location (point 1) as used for the modal analysis (Fig. 21). The FE models are consequently used to calculate eigenmodes and direct frequency responses using a Nastran FE solver. To assess the numerical models, MAC matrices and FRFs are calculated to examine the correlation with the tested samples for the 


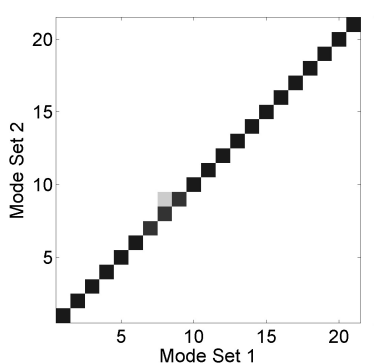

(a) Adhesive bonding

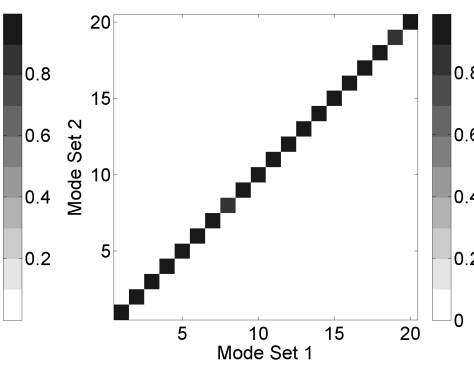

(b) MIG

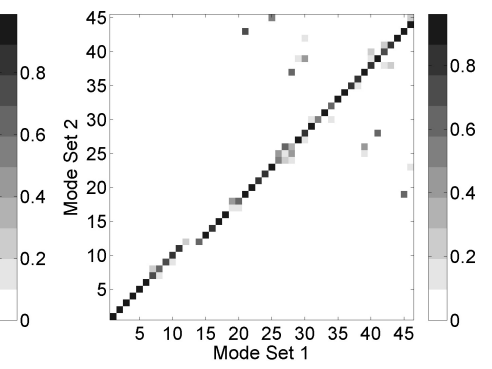

(c) RSW

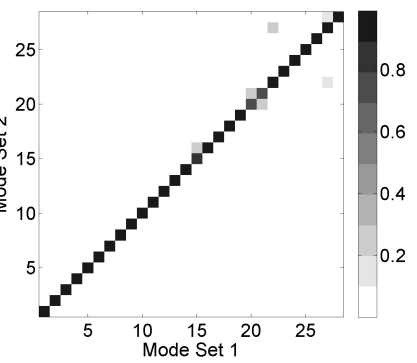

(d) FDS

Figure 15. MAC for two of the tested joined plates per connection

Table 5. Average damping loss factor values calculated with the PIM for the joined plate systems for the four connection types

\begin{tabular}{ccccc}
\hline Center frequency $[\mathrm{Hz}]$ & Adhesive bonding & MIG & RSW & FDS \\
\hline $\mathbf{1 0 0}$ & 0.0022 & 0.0020 & 0.0053 & 0.0013 \\
$\mathbf{3 0 0}$ & 0.0038 & 0.0036 & 0.0040 & 0.0013 \\
$\mathbf{5 0 0}$ & 0.0027 & 0.0019 & 0.0026 & 0.0008 \\
$\mathbf{7 0 0}$ & 0.0011 & 0.0010 & 0.0024 & 0.0009 \\
$\mathbf{9 0 0}$ & 0.0016 & 0.0010 & 0.0028 & 0.0008 \\
\hline Mean & 0.0022 & 0.0019 & 0.0034 & 0.0011 \\
\hline Mean min & 0.0018 & 0.0013 & 0.0027 & 0.0008 \\
Mean max & 0.0027 & 0.0025 & 0.0044 & 0.0013 \\
\hline
\end{tabular}

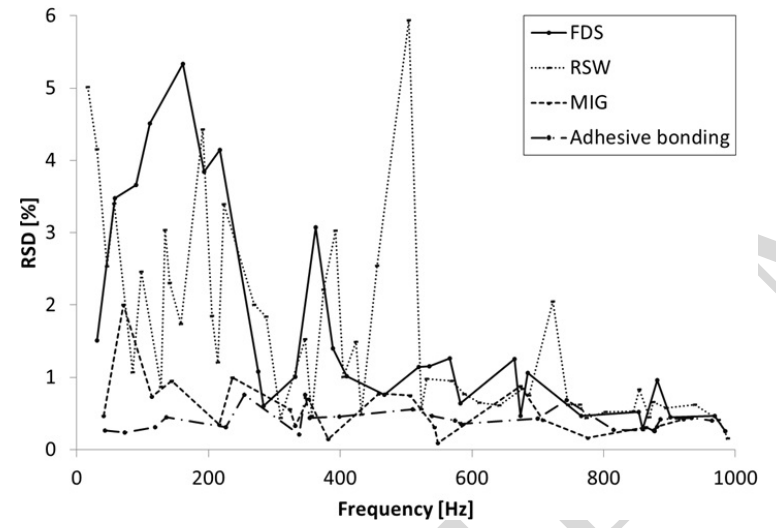

Figure 16. Comparison of the RSDs of the resonance frequencies for the tested joined plates

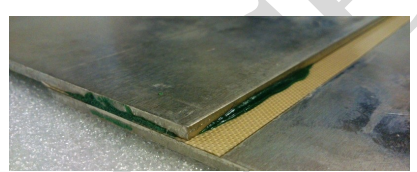

(a)

(b)

Figure 17. Excess glue and Teflon tape residue influence on width and thickness of bonding for adhesive bonded plates

normal modes and direct frequency responses up to 1000 Hz. In the simulations, no parameter updating is performed. In what follows, the FE model of each connection type and the comparison between simulations and measurements is discussed.

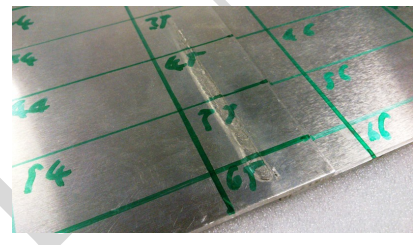

(a)

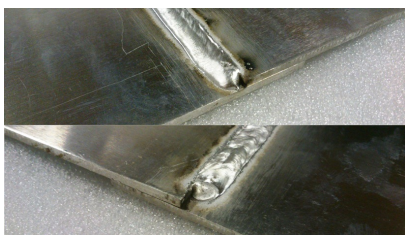

(b)
Figure 18. MIG weld protrusion and weld bead variation

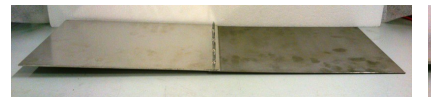

(a)

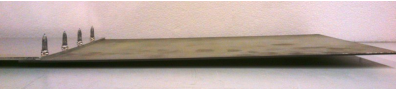

(b)
Figure 19. Cutting induced bending present in the FDS joined plates

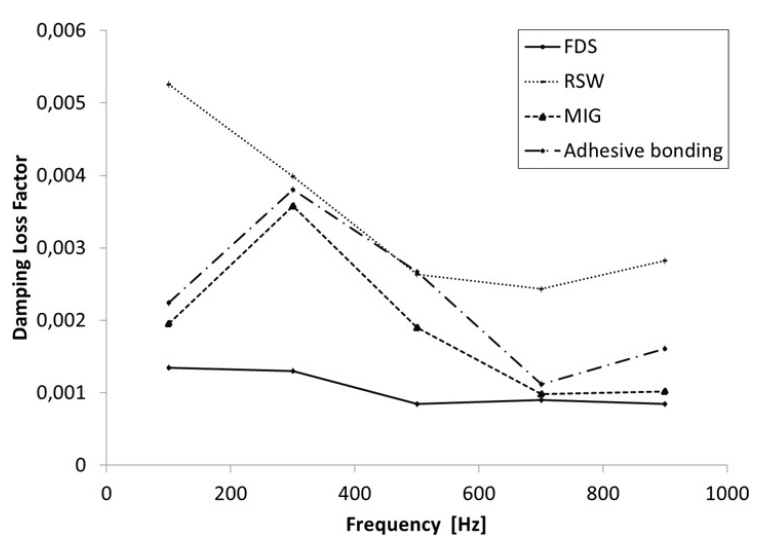

Figure 20. Comparison of the damping loss factors for the tested joined plates 


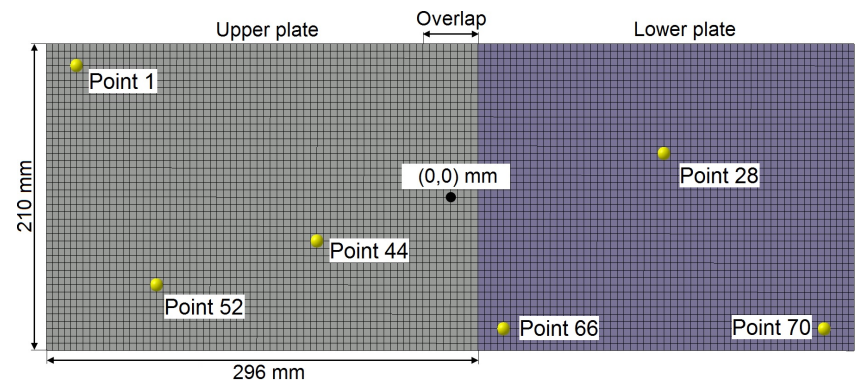

Figure 21. Numerical connection model with excitation (Point 1) and sensor (Points 28, 44, 52, 66 and 70) positions (Table 4)

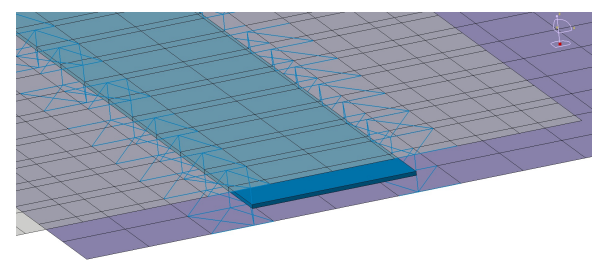

Figure 22. Generic Glue Connection with Nastran|CHEXA+MPC modeling property

\subsection{Adhesive bonding}

6.1.1 Numerical model Before introducing the Generic Glue Connection, the spacing between both plate meshes is set to be the sum of the mean of both plate thicknesses and the glue thickness. Since the glue application with microbeads yields a glue thickness of $0.3 \mathrm{~mm}$, the distance between both flanges is $2.8 \mathrm{~mm}$. The Generic Glue Connection is considered as a line type connection and allows defining the location of the glue strip using both mesh-independent geometric coordinates based and a meshfeature based description. The connection line is defined in the middle of the overlap over the entire width of the sample, at an equal distance between both plate meshes. A line discretization parameter, determining the number of elements along the bonding, of $5 \mathrm{~mm}$ is used, corresponding to the plate meshes. The glue strip width is set to $12.5 \mathrm{~mm}$ according to the design specification.

Isotropic material parameters are used for the Sika glue (Table 1). The inserted connections are only generic entities linking the different components. Consequently, a choice has to be made for an appropriate connection property. The holistic Virtual.Lab environment allows the use of Automatic Generic Properties for the available connections, increasing the degree of automation for the creation of connections. For adhesive bonding, a Nastran|CHEXA+MPC connection property is used, corresponding to the eventually used solver. This yields a glue mesh that consists of 42 HEXA8 elements along the defined line, connected to the plate meshes through 172 Rigid Spider (RBE2) and 172 Multiple Point Constraint
Table 6. Comparison of first six simulated $\left(f_{\text {num }}\right)$ and measured $\left(f_{\text {meas }}\right)$ eigenfrequencies for adhesive bonding

\begin{tabular}{c|ccc}
\hline Mode & $f_{\text {num }}[\mathrm{Hz}]$ & $f_{\text {meas }}[\mathrm{Hz}]$ & $\Delta[\%]$ \\
\hline $\mathbf{1}$ & 42.2 & 42.8 & $-1.42 \%$ \\
$\mathbf{2}$ & 73.3 & 73.3 & $0 \%$ \\
$\mathbf{3}$ & 119.2 & 118.9 & $0.25 \%$ \\
$\mathbf{4}$ & 137.9 & 136.7 & $0.87 \%$ \\
$\mathbf{5}$ & 223.9 & 227.2 & $-1.47 \%$ \\
$\mathbf{6}$ & 254.8 & 256.6 & $-0.71 \%$ \\
\hline
\end{tabular}

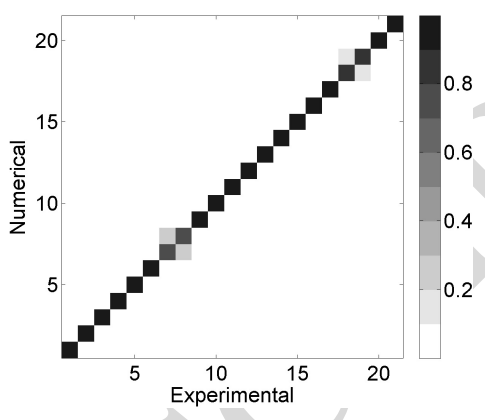

Figure 23. MAC between measurement and simulation for adhesive bonding
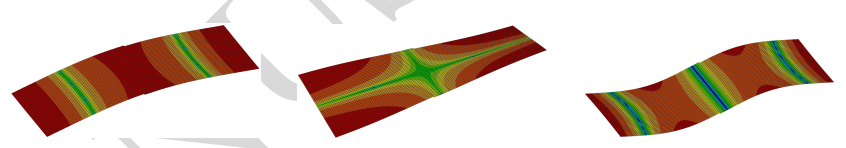

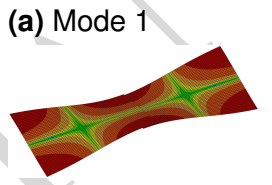

(d) Mode 4 (b) Mode 2

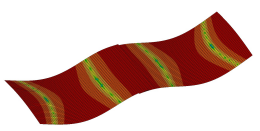

(e) Mode 5 (c) Mode 3

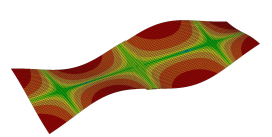

(f) Mode 6
Figure 24. First six simulated modes for adhesive bonding

elements. The resulting model is shown in Fig. 22. Each HEXA8 element is $0.3 \mathrm{~mm}$ high, $5 \mathrm{~mm}$ wide and $12.5 \mathrm{~mm}$ long, where one element is used in the thickness direction. These solid elements are connected at each node using an RBE2 element with an MPC to the nodes of adjacent shell elements of the plates.

6.1.2 Comparison of results For the adhesive bonding connection, the natural frequencies show very good agreement (Table 6). The simulated mode shapes corresponding to these frequencies are shown for this connection in Fig. 24. The MAC matrix (Fig. 23) shows a very good correlation, with near unity diagonal values, and some slightly lower values and off-diagonality for the 7 th and 8th mode and for the 18th and 19th mode. Overall, the numerical model accurately represents the mode shapes. As discussed in Section 5.1, similar results are obtained for the MAC matrix of the measured adhesive bonded samples, also showing high mutual correlation.

In Fig. 25, FRFs are shown comparing the direct frequency responses of the numerical model to the measured responses 


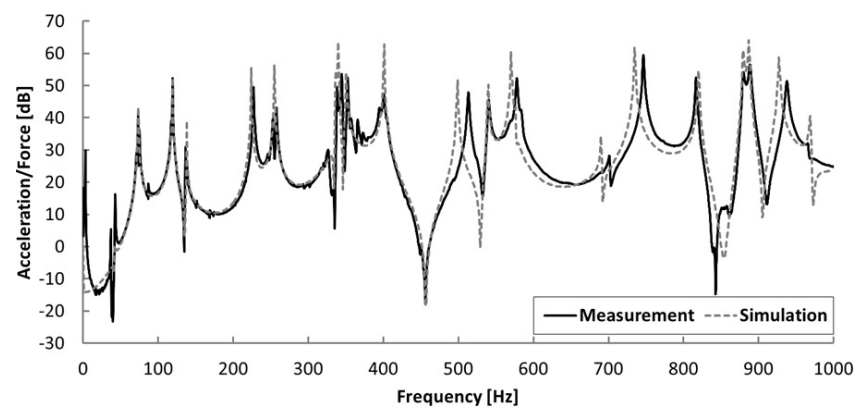

(a) FRF Point 1 - Point 28

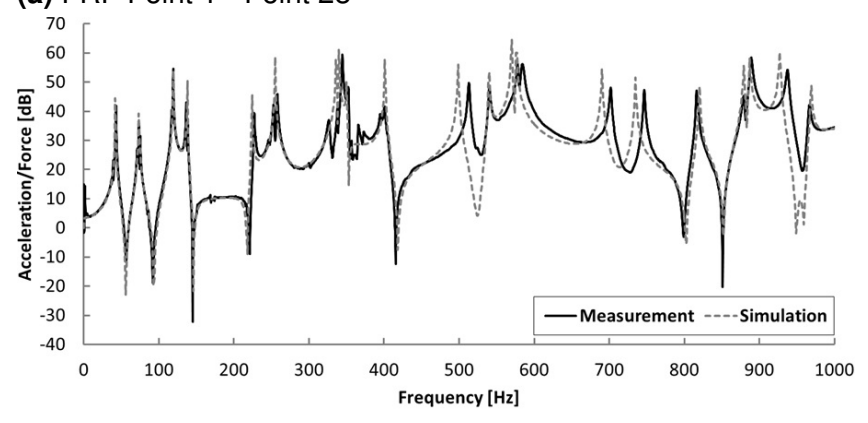

(b) FRF Point 1 - Point 44

Figure 25. Comparison of the FRFs for adhesive bonding between simulation (-- ) and measurement (-)

for one of the samples. For the sake of conciseness, two FRFs are presented for each connection type, considering a response location on either side of the joint region, while the excitation location is located near a corner in order to excite as many modes as possible. It has been verified for all four connection types that the comparison with the FRFs in the other response locations leads to the same conclusions. In these FRFs, the excitation location corresponds to Point $1((-0.2565,0.09) \mathrm{m}$ for adhesive Bonding, ( -0.2675 , $0.09) \mathrm{m}$ for MIG welding, $(-0.2675,0.09) \mathrm{m}$ for RSW and $(-0.268,0.09) \mathrm{m}$ for FDS $)$ in Fig. 21, while the response locations are Points 28 and Point 44 respectively. A very good agreement is found. The mean structural damping values, used for the plate materials in the numerical model, seem to correspond well. In the frequency range around the 7th $(336.4 \mathrm{~Hz})$ and 8 th mode $(339.8 \mathrm{~Hz})$, the measurement shows some noise, which is reflected in the MAC matrix.

Possible causes for differences between simulations and measurements have already been mentioned in Section 5.1. Deviations in applied glue width and thickness, together with Teflon tape residue could slightly alter the results. In all the modeled connections, no gap or contact is included at the overlap between the plates. This could lead to problems at higher frequencies, due to contact between the plates, especially for the point connections. As this leads to local nonlinearities, a modified model would be required. In this case, in the considered frequency range, the numerical

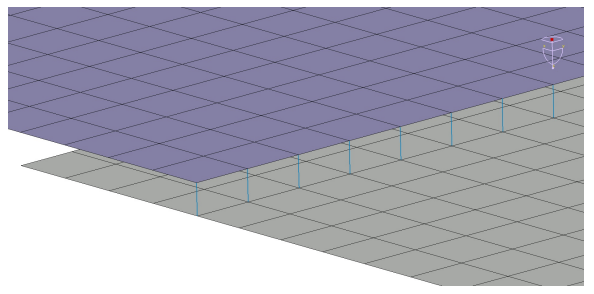

Figure 26. Generic Seam Weld Connection with Nastran|RBE2 modeling property

model shows an overall very good agreement with the measurements.

\section{$6.2 M I G$}

6.2.1 Numerical model Similar to the adhesive bonding, the MIG welding is a line type connection. The Generic Seam Weld Connection is used to represent the MIG weld line. The weld line is specified at the edge of the bottom plate over the entire width. For the line discretization, the element size of $5 \mathrm{~mm}$ is used. The height of the weld connection is set to be the distance between the meshes of both plates, corresponding to the distance of $2.5 \mathrm{~mm}$ between their midsurfaces. A Nastran|RBE2 connection property is used to represent the MIG weld, resulting in a weld mesh comprised of 43 RBE2 (Rigid Spider) elements (corresponding to the 43 nodes over the plate width), as shown in Fig. 26.

The connection is made on a closest-node basis, suited for the envisaged mesh-independent applications. The FE meshes of the plates are designed such that these corresponding nodes are on a line allowing for RBE2 elements perpendicular to both supports. This way, possible misalignment influences in the numerical representation are avoided. It is noted that no heat affected zone is taken into account in this automatic, mesh-independent modeling approach.

6.2.2 Comparison of results For the MIG weld connection, the natural frequencies show good agreement (Table 7). The MAC matrix in Fig. 27 shows that the modes in the frequency range of interest correlate well. Some mode switching occurs around the 7th and 8th mode and around the 19th and 20th mode, corresponding to the zones of lower MAC values in the comparison between measured samples. Just like the adhesive bonded samples, the measurements showed high mutual correlation.

By comparing the simulated and measured FRFs (Fig. 28 ) it is seen that the experiments seem to miss a mode at $549.9 \mathrm{~Hz}$ which is the skipped mode in the MAC matrix. Besides this slight deviation, the FRFs show a very good agreement. The damping values used for the single 
Table 7. Comparison of first six eigenfrequencies between simulations $\left(f_{\text {num }}\right)$ and measurements $\left(f_{\text {meas }}\right)$ for MIG welding

\begin{tabular}{c|ccc}
\hline Mode & $f_{\text {num }}[\mathrm{Hz}]$ & $f_{\text {meas }}[\mathrm{Hz}]$ & $\Delta[\%]$ \\
\hline $\mathbf{1}$ & 39.6 & 41.5 & $-4.80 \%$ \\
$\mathbf{2}$ & 67.0 & 69.2 & $-3.28 \%$ \\
$\mathbf{3}$ & 111.5 & 115.5 & $-3.59 \%$ \\
$\mathbf{4}$ & 136.1 & 142.0 & $-4.34 \%$ \\
$\mathbf{5}$ & 212.5 & 215.7 & $-1.51 \%$ \\
$\mathbf{6}$ & 235.1 & 233.2 & $0.81 \%$ \\
\hline
\end{tabular}

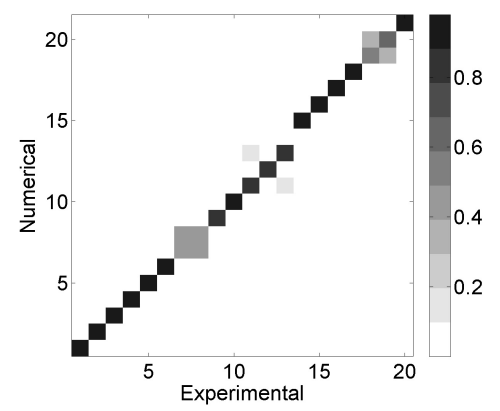

Figure 27. MAC between measurement and simulation for MIG welding

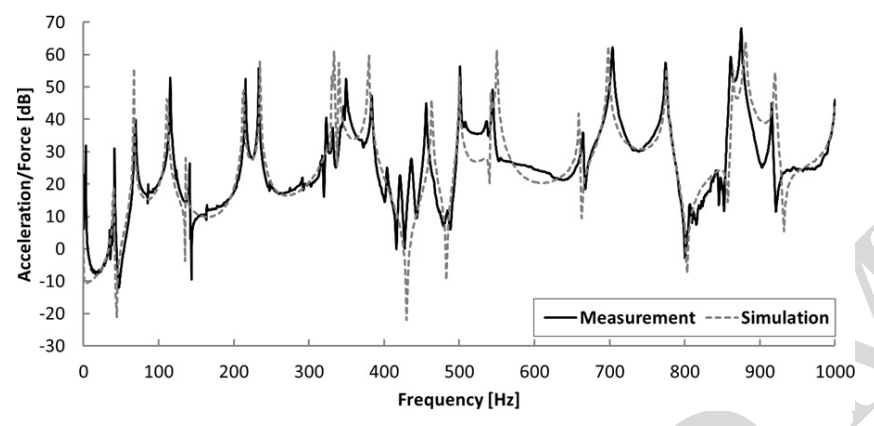

(a) FRF Point 1 - Point 28

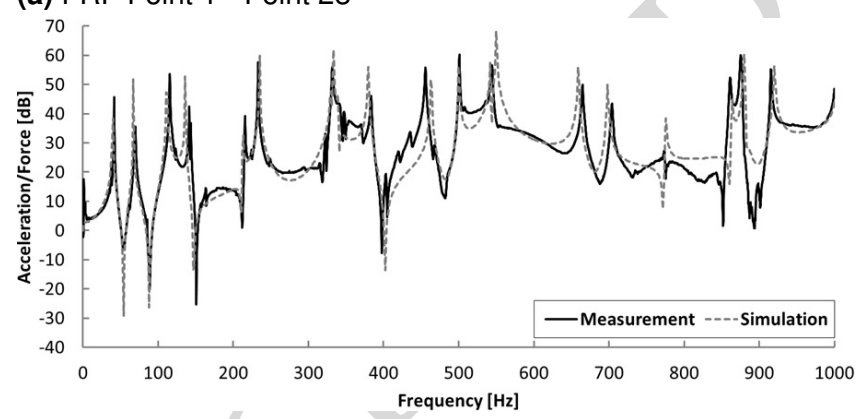

(b) FRF Point 1 - Point 44

Figure 28. Comparison of the FRFs for MIG welding between simulation (--) and measurement $(-)$

plates lead to good correspondence between simulation and experiment.

Some possible causes for differences have been discussed in Section 5.1. Additionally to a lower repeatability as compared to the adhesive bonding, this joining technique might induce local stresses. Moreover, there could be an influence of changed properties in a heat affected zone around the weld, especially for those samples in which the welding line protrudes to the other side. These

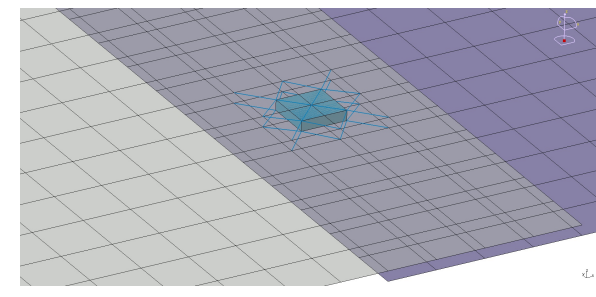

Figure 29. Generic Spot Weld Connection with Nastran| CHEXA+RBE3 modeling property

effects are not taken into account, using the Generic Seam Weld Connection, to allow for a mesh-independent joint representation. However, good mutual correlation in the considered frequency range between the test samples indicates that the latter is not of big influence. Overall, the used model for the MIG welded samples shows good applicability for the NVH simulations.

\subsection{RSW}

6.3.1 Numerical model As opposed to the adhesive bonding and MIG welding joining technologies, the RSW connection is a pointwise connection, for which the Generic Spot Weld Connection is used. The spot welds are located centrally between both plate meshes, in the middle of the overlap, with a mutual separation of $50 \mathrm{~mm}$ and a distance of $30 \mathrm{~mm}$ from the edge. The nominal spot weld diameter of $5 \mathrm{~mm}$ is used, while the height is the distance between both flanges, connecting the midplane surfaces of both supports. For the spot weld material, undamped aluminum 6016-T4 is used, since the damping contribution of the connection was found to be negligible for the supports and frequency range considered. The Nastran|CHEXA+RBE3 connection property is used, giving rise to a mesh consisting of 4 HEXA8 elements connected with both plate meshes through 32 Interpolation Spiders (RBE3), as shown in Fig. 29.

One spot weld is represented by one HEXA8 element, of $1 \mathrm{~mm}$ height and $4.43 \mathrm{~mm}$ edge length, corresponding respectively to the distance between the neutral lines of both plates and to the spot weld area for a $5 \mathrm{~mm}$ diameter. Each node of the HEXA8 elements is connected to the 4 closest nodes on the adjacent plate mesh through RBE3 interpolating elements. Meshes of both plates are again designed to have node centered connections to avoid possible misalignment influences of nodes on both flanges. No heat affected zone is taken into account.

6.3.2 Comparison of results For the RSW connection, the natural frequencies from Table 8 show good agreement. Since thinner plates are joined, a larger number of modes is found in the considered frequency range. The MAC matrix 
Table 8. Comparison of first six eigenfrequencies between simulations $\left(f_{\text {num }}\right)$ and measurements $\left(f_{\text {meas }}\right)$ for RSW

\begin{tabular}{c|ccc}
\hline Mode & $f_{\text {num }}[\mathrm{Hz}]$ & $f_{\text {meas }}[\mathrm{Hz}]$ & $\Delta[\%]$ \\
\hline $\mathbf{1}$ & 15.6 & 17.6 & $-12.8 \%$ \\
$\mathbf{2}$ & 27.2 & 29.6 & $-8.82 \%$ \\
$\mathbf{3}$ & 44.2 & 47.5 & $-7.47 \%$ \\
$\mathbf{4}$ & 54.9 & 54.8 & $0.18 \%$ \\
$\mathbf{5}$ & 83.6 & 85.4 & $-2.15 \%$ \\
$\mathbf{6}$ & 94.5 & 95.6 & $-1.16 \%$ \\
\hline
\end{tabular}

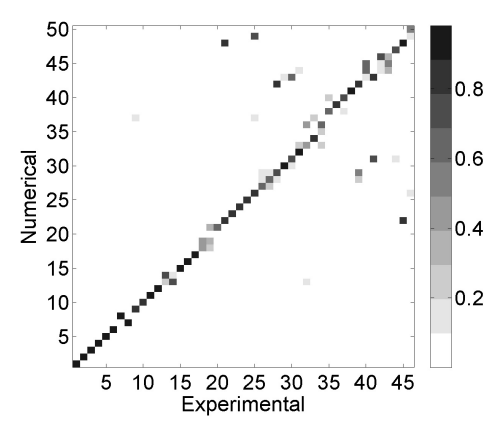

Figure 30. MAC between measurement and simulation for RSW

in Fig. 30 shows that the modes in the frequency range of interest have a quite good overall correlation. At higher frequencies, some scatter is found. This corresponds to the measurements, as they show a quite good mutual correlation, with similar scatter present in the same frequency region.

The simulated and measured FRFs in Fig. 31 show good agreement up to around $300 \mathrm{~Hz}$. For higher frequencies, some shifts arise. As mentioned before, this can be explained by similar discrepancies in the measurement results in that frequency range. This could be caused by the spot welding process locally affecting the material parameters, while the diameter and locations of the spot welds could slightly vary. Also here the used damping values yield good agreement.

\subsection{FDS}

6.4.1 Numerical model The FDS connection technology has no dedicated representation in the holistic simulation environment. It has been decided to use the pointwise Generic Screw Connection type, as the technique still includes screws. The locations of the screws are the same as for the spot welds. Screw parameters are chosen according to the nominal screw dimensions: a screw diameter of $5 \mathrm{~mm}$, screw head diameter of $13 \mathrm{~mm}$ and maximum screw length of $24 \mathrm{~mm}$. The Nastran|RBE2+Spider connection property is chosen, yielding a mesh composition of 4 Rigid Spider (RBE2) elements, connecting 9 nodes per spider, as shown in Fig. 32.

Each screw is represented by a Rigid Spider element, connecting plate nodes and a node located centrally between both plates. The connected nodes on the plate faces are those

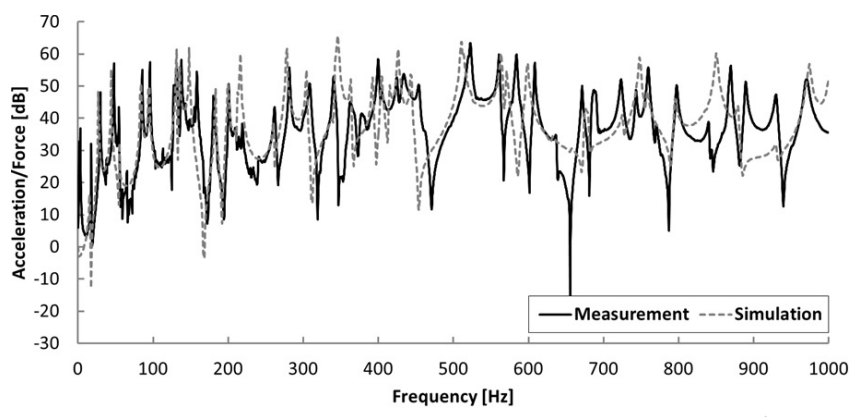

(a) FRF Point 1 - Point 28

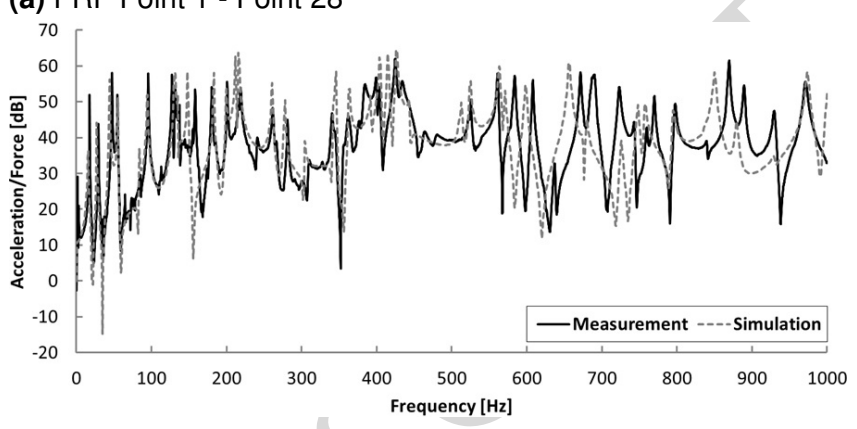

(b) FRF Point 1 - Point 44

Figure 31. Comparison of the FRFs for RSW between simulation (--) and measurement $(-)$

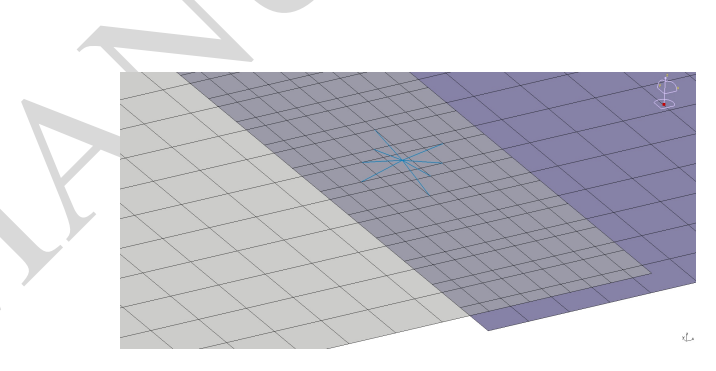

Figure 32. Generic Screw Connection with Nastran|RBE2+Spider modeling property

lying in the region between the screw head diameter and the screw diameter. This corresponds to a screw-nut connection rather than the result from the FDS process. Besides this, no pilot holes on the steel plate nor the mass addition of the screw is taken into account. This might lead to more discrepancies between simulation and measurements than for the other connection types.

6.4.2 Comparison of results For the FDS joining the natural frequencies are relatively close (Table 9). The MAC matrix in Fig. 33 shows that the modes in the frequency range of interest have an overall good correlation, comparable to the measurement results, yet showing some lower correlation. The measurements indicate good matching between some of the measured samples, however some show lower correlation for higher frequency modes. This might be explained by a possible repeatability-issue of the FDS process (local heat generation, material deformation and possible misalignment with the pilot holes) while also the 
Table 9. Comparison of first six eigenfrequencies between simulations $\left(f_{\text {num }}\right)$ and measurements $\left(f_{\text {meas }}\right)$ for FDS

\begin{tabular}{c|ccc}
\hline Mode & $f_{\text {num }}[\mathrm{Hz}]$ & $f_{\text {meas }}[\mathrm{Hz}]$ & $\Delta[\%]$ \\
\hline $\mathbf{1}$ & 29.4 & 31.3 & $-6.46 \%$ \\
$\mathbf{2}$ & 52.0 & 56.2 & $-8.08 \%$ \\
$\mathbf{3}$ & 86.5 & 91.1 & $-5.32 \%$ \\
$\mathbf{4}$ & 104.9 & 106.8 & $-1.81 \%$ \\
$\mathbf{5}$ & 159.5 & 163.8 & $-2.70 \%$ \\
$\mathbf{6}$ & 179.4 & 186.8 & $-4.12 \%$ \\
\hline
\end{tabular}

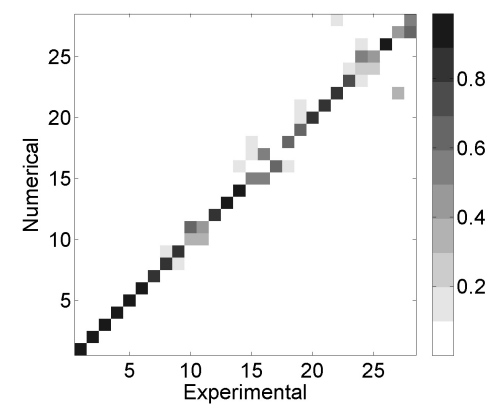

Figure 33. MAC between measurement and simulation for FDS

curvature of the steel plates might be of influence. Moreover, as discussed before, the numerical screw connection model seemed to be the least representative of all joining models considered here.

The FRFs (Fig. 34) show rather good agreement in the lower frequency range. From around $200 \mathrm{~Hz}$ some shifts occur, while in the higher frequency region more outspoken differences are present. Considering that the produced FDS samples show the largest variation, because of larger variations in both the plates and connections, the nondedicated screw connection model still yields reasonable results, mainly at lower frequencies. As for the previous joining techniques, it is seen that also here the damping values used for the plate materials lead to a rather good agreement. This indicates that the approach of calculating and using the damping loss factors on single plate level, for the frequency range and connections considered, leads to an accurate representation of the damping in the joined systems.

\section{Conclusion}

This work, set within the scope of the European FP7 ALIVE project, presents an experimental validation of numerical structural dynamic models for four different joining techniques. The joining technologies considered are adhesive bonding, metal inert gas (MIG) welding, resistance spot welding (RSW) and flow drill screwing (FDS), which are applied to joined A4 sized plates of three different materials Al 6082-T6, Al 6016-T4 and phs-ultraform 1500. The objective of this study is to assess the accuracy of predefined, generic and mesh-independent connection

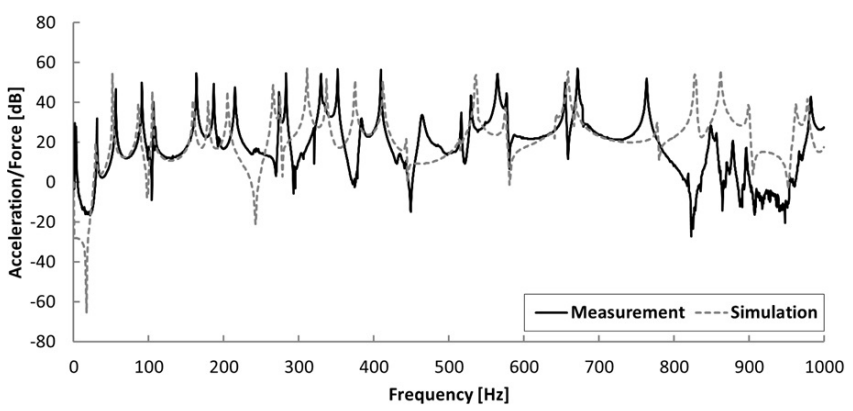

(a) FRF Point 1 - Point 28

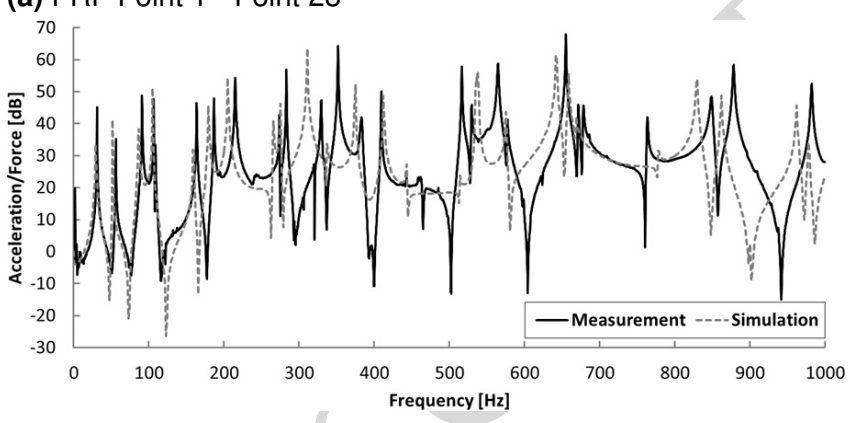

(b) FRF Point 1 - Point 44

Figure 34. Comparison of the FRFs for FDS between simulation $(--)$ and measurement $(-)$

modeling in the Virtual.Lab holistic simulation environment to represent the dynamic behavior of the considered joining techniques.

An experimental modal analysis has been carried out on both single and joined A4 plates and the Power Injection Method has been applied to estimate damping coefficients. Both the single and joined plates show a good repeatability. Moreover, in the considered frequency range, no substantial influence of the different joining techniques is found on the damping values. The numerical Finite Element models of the plates (with experimentally obtained damping values) are joined using either the Generic Glue, Seam Weld, Spot Weld or Screw Connection, all present in the simulation environment. A good to very good correlation is found for the Generic Glue and Seam Weld Connections. Also the Spot Weld Connection model shows good correspondence to the experimental results, albeit less than for the continuous joining techniques. For the flow drill screwing technology, for which no dedicated connection model is available in the holistic environment, less but still reasonable agreement is found between a standard screw model and experiment. In all models, damping is accurately accounted for. The studied generic joint models show a high modeling accuracy and can be applied for structural dynamic simulations for the considered joining techniques. 


\section{Funding}

The European Commission is gratefully acknowledged for its support of the ALIVE research project (GA 314234). The Research Fund KU Leuven is acknowledged for its support. The research of L. Van Belle and E. Deckers is funded by grants from the Research Foundation - Flanders (F.W.O.).

\section{References}

ALIVE (2012) Advancing high volume affordable lightweighting for future electric vehicles. www.project-alive.eu. Accessed: 2015-12-08.

Alvarez RDA, Ferguson NS and Mace BR (2014) A robust spot weld model for structural vibration analysis. Finite Elements in Analysis and Design 89: 1-7.

Anderson GP, Devries KL and Williams ML (1973) Finite element in adhesion analyses. International Journal of Fracture 9(4): 421-436.

Aruleswaran A, Balkwill J and Morrey D (2001) Dynamic behaviour of a structure featuring adhesive bonded joint. In: Proceedings of SPIE, the International Society for Optical Engineering, volume 4359. Society of Photo-Optical Instrumentation Engineers, pp. 238-244.

Aygül M (2012) Fatigue analysis of welded structures using the finite element method .

Bies DA and Hamid S (1980) In situ determination of loss and coupling loss factors by the power injection method. Journal of Sound and Vibration 70(2): 187-204.

Bloss B and Rao MD (2002) Measurement of damping in structures by the power input method. Experimental Techniques 26(3): $30-32$.

Carfagni M and Pierini M (1999a) Determining the loss factor by the Power Input Method (PIM), Part 1: Numerical investigation. Journal of Vibration and Acoustics 121: 417421.

Carfagni M and Pierini M (1999b) Determining the loss factor by the Power Input Method (PIM), Part 2: Experimental investigation with impact hammer excitation. Journal of Vibration and Acoustics 121: 422-428.

Chee NC and Bakar ARA (2007) Finite element modeling of arc welded joints. Jurnal Mekanikal (23): 15-30.

Clarkson BL and Ranky MF (1984) On the measurement of the coupling loss factor of structural connections. Journal of Sound and Vibration 94(2): 249-261.

Cremer L, Heckl M and Petersson BAT (2005) Structure-borne sound: Structural Vibrations and Sound Radiation at Audio Frequencies. 3rd edition. Springer Science \& Business Media. da Silva LFM, Öchsner A and Adams R (2011) Handbook of adhesion technology, volume 2. Springer Science \& Business Media.

De Langhe K and Sas P (1996) Statistical analysis of the power injection method. The Journal of the Acoustical Society of America 100(1): 294-303.

Dourado MDM and de Meireles JFB (2014) A simplified finite element riveted lap joint model in structural dynamic analysis. In: Advanced Materials Research, volume 1016. Trans Tech Publ, pp. 185-191.

Eriksson A, Lignell AM, Olsson C and Spennare H (2003) Weld evaluation using FEM: a guide to fatigue-loaded structures.

Fahy F and Kalnins A (1987) Sound and structural vibration radiation, transmission, and response by Frank Fahy. The Journal of the Acoustical Society of America 81(5): 16511651.

Fayard JL, Bignonnet A and Van KD (1997) Fatigue design of welded thin sheet structures. European Structural Integrity Society 22: $145-152$.

Gagliardini L, Houillon L, Borello G and Petrinelli L (2005) Virtual SEA-FEA-based modeling of mid-frequency structure-borne noise. Sound and vibration 39(1): 22.

Groover MP (2007) Fundamentals of modern manufacturing: materials processes, and systems. 3rd edition. John Wiley \& Sons.

Gunes R, Apalak MK and Yildiri M (2007) The free vibration analysis and optimal design of an adhesively bonded functionally graded single lap joint. International Journal of Mechanical Sciences 49(4): 479-499.

Hatifi MM, Firdaus MH and Razlan AY (2014) Modal analysis of dissimilar plate metal joining with different thicknesses using MIG welding. International Journal of Automotive and Mechanical Engineering 9: 1723.

He K and Zhu WD (2011) Finite element modeling of structures with L-shaped beams and bolted joints. Journal of Vibration and Acoustics 133(1): 011011.

He X (2011) A review of finite element analysis of adhesively bonded joints. International Journal of Adhesion and Adhesives 31(4): 248-264.

He X (2012a) Application of finite element analysis in sheet material joining. INTECH Open Access Publisher.

He X (2012b) Numerical and experimental investigations of the dynamic response of bonded beams with a single-lap joint. International Journal of Adhesion and Adhesives 37: 79-85.

He X (2014) Finite element analysis of torsional free vibration of adhesively bonded single-lap joints. International Journal of Adhesion and Adhesives 48: 59-66. 
He X and Oyadiji SO (2001) Influence of adhesive characteristics on the transverse free vibration of single lap-jointed cantilevered beams. Journal of Materials Processing Technology 119(1): 366-373.

He X, Pearson I and Young KW (2007a) Finite element analysis of self-pierce riveted joints. In: Key Engineering Materials, volume 344. Trans Tech Publ, pp. 663-668.

He X, Pearson I and Young KW (2007b) Three dimensional finite element analysis of transverse free vibration of self-pierce riveting beam. In: Key Engineering Materials, volume 344. Trans Tech Publ, pp. 647-654.

Heylen W, Lemmens S and Sas P (2014) Modal analysis theory and testing. KU Leuven, PMA division.

Horton C, Gurgenci H, Veidt M and Friswell MI (1999) Finite element model updating of the welded joints in a tubular $\mathrm{H}-$ frame. In: Imac-Proceedings of the 17th International Modal Analysis Conference, Vols I and Ii, volume 3727. Society of Experimental Engineers, pp. 1556-1562.

Kaya A, Tekelioğlu MS and Findik F (2004) Effects of various parameters on dynamic characteristics in adhesively bonded joints. Materials letters 58(27): 3451-3456.

Kim J, Yoon JC and Kang BS (2007) Finite element analysis and modeling of structure with bolted joints. Applied Mathematical Modelling 31(5): 895-910.

Kinloch AJ (1987) Adhesion and adhesives: Science and technology. London: Chapman and Hall.

Krank B, Ohlsson U, Hedlund A, Nordström L, Englund T and Göransson P (2012) Tuning spot weld models for vehicle body structural dynamics. In: International Conference on Noise and Vibration Engineering (ISMA)/International Conference on Uncertainty in Structural Dynamics (USD), KU Leuven, Dept Mech Engn, Leuven, Belgium, Sep 17-19, 2012. pp. 39153926.

Kuratani F, Matsubara K and Yamauchi T (2011) Finite element model for spot welds using multi-point constraints and its dynamic characteristics. SAE International Journal of Passenger Cars-Mechanical Systems 4(2011-01-1697): 13111319

Kwon YD, Kwon HW, Hwangbo JH and Jang SH (2006) Finite element modeling for static and dynamic analysis of structures with bolted joint. In: Key Engineering Materials, volume 306. Trans Tech Publ, pp. 547-552.

Lardeur P, Scigliano R and Scionti M (2012) Verification and validation for the vibration study of automotive structures modelled by finite elements. The Journal of Strain Analysis for Engineering Design : 0309324712466508.

Libardi AL and Vartoto PS (2004) Experimental determination of loss factors on coupled structures using the power injection method. In: Proceedings of IMAC XXII

Martinez JAO, Jordan R and Calçada M (2009) Analysis of the Application of the Power Injection Method to Damping Evaluation of Reinforced Structures. In: Proceedings of COBEM 2009.

Miller SF, Li R, Wang H and Shih AJ (2006) Experimental and numerical analysis of the friction drilling process. Journal of Manufacturing Science and Engineering 128(3): 802-810.

Minnick WH (2007) Gas Metal Arc Welding Handbook. 5th edition. The Goodheart-Willcox Company, Inc.

Niemi E (1995) Stress determination for fatigue analysis of welded components. Woodhead Publishing.

Niemi E and Marquis GB (2003) Structural hot spot stress method for fatigue analysis of welded components. In: International Conference on Metal Structures, Miscolc, Hungary. pp. 39-44.

Ouisse M and Cogan S (2010) Robust design of spot welds in automotive structures: A decision-making methodology. Mechanical Systems and Signal Processing 24(4): 1172-1190.

Palmonella M, Friswell MI, Mottershead JE and Lees AW (2004) Guidelines for the implementation of the CWELD and ACM2 spot weld models in structural dynamics. Finite elements in analysis and design 41(2): 193-210.

Palmonella M, Friswell MI, Mottershead JE and Lees AW (2005) Finite element models of spot welds in structural dynamics: review and updating. Computers \& Structures 83(8-9): 648661.

Radoičić G and Jovanović M (2013) Experimental identification of overall structural damping of system. Strojniški vestnik-Journal of Mechanical Engineering 59(4): 260-268.

Rose T (2002) An approach to properly account for structural damping, frequency-dependent stiffness/damping, and to use complex matrices in transient response. In: Worldwide Aerospace Conference \& Technology Showcase.

Sauer RA (2016) A survey of computational models for adhesion. The Journal of Adhesion 92: 81-120.

Shokrollahi S and Adel F (2016) Finite element model updating of bolted lap joints implementing identification of joint affected region parameters. Journal of Theoretical and Applied Vibration and Acoustics 2(1): 65-78.

Siemens PLM Software (2015a) LMS Test.Lab R13 User's Manual. Siemens PLM Software (2015b) LMS Virtual.Lab R13 User's Manual.

Skovron JD, Prasad R, Ulutan D, Mears L, Detwiler D, Paolini D, Baeumler B and Claus L (2015) Effect of thermal assistance on the joint quality of al6063-t5a during flow drill screwdriving. Journal of Manufacturing Science and Engineering 137(5): 051019 . 
Sønstabø JK, Holmstrøm PH, Morin D and Langseth M (2015) Macroscopic strength and failure properties of flow-drill screw connections. Journal of Materials Processing Technology 222: $1-12$.

Sønstab $\varnothing$ JK, Morin D and Langseth M (2016) Macroscopic modelling of flow-drill screw connections in thin-walled aluminium structures. Thin-Walled Structures 105: 185-206.

Vaziri A, Nayeb-Hashemi H and Hamidzadeh HR (2004) Experimental and analytical investigations of the dynamic response of adhesively bonded single lap joints. Journal of vibration and acoustics 126(1): 84-91.

Wu G and Crocombe AD (1996) Simplified finite element modelling of structural adhesive joints. Computers \& Structures 9(4): 421-436.

Xu S and Deng X (2004) An evaluation of simplified finite element models for spot welded joints. Finite Elements in Analysis and Design 40(9-10): 1175-1194.

Zhang H and Senkara J (2005) Resistance welding: Fundamentals and Applications. CRC Press.

Zienkiewicz OC, Taylor RL, Zhu JZ and Nithiarasu P (2005) The Finite Element Method - The three volume set. 6th edition. Butterworth-Heinemann. 